\title{
Damage Evaluation in Shells from Changes in Its Static Parameters
}

\author{
Sandra I. Robles and Néstor F. Ortega*
}

Engineering Department, Universidad Nacional del Sur, Av Alem 1253, 8000 Bahía Blanca, Argentina

\begin{abstract}
Displacements of a structure depend on its geometry, properties of the material and acting loads. The presence of cracks in the structures originates local rigidity changes affecting its static and dynamic behavior. In this paper different methodologies for damage identification, based on the static response of reinforced concrete shells are formulated. The first three damage analysis stages, namely, detection, location and quantification are analysed using as study parameters the vertical displacement, elastic curvature, elastic curvature variation and volumetric displacements. Numerical simulations were carried out, with models analyzed by the Finite Element Method. In order to validate the damage identification capability of the proposed methodologies the sensitivities of the various parameters proposed for damage identification were investigated.
\end{abstract}

Keywords: Shell, crack, damage detection, displacement, static response.

\section{INTRODUCTION}

The structures in normal service can be exposed to factors like impact loads, wind, earthquakes, corrosion, fatigue and aging among others. These factors can damage the structural elements by reducing the structural stiffness at the damaged zone thus changing its static and dynamic behavior. In order to monitor the integrity of structures periodically a non destructive damage evaluation technique is necessary. A structural damage evaluation technique, based on non destructive tests, addresses the problem of how to detect, locate and quantify damage that occurred in a structure by using the observed modifications of its dynamic and/or static behaviour. Among the non-destructive methods of damage detection are those which consider the changes in the dynamic response of the structure, i.e. natural frequencies, mode shapes, etc. These have been treated by several authors so there is a vast collection of publications of this topic [1-8].

In relation to non-destructive methods of damage detection that consider the changes in the static response of the structures, i.e. displacement variations and/or strain, there are few publications [9-14], even though normally, the design and analysis of a great quantity of civil structures, is carried out with this type of loads.

Depending on the analyzed structure and the equipment availability to make the measurements in situ, one method, dynamic or static, could be more convenient than another, and in some cases, complementary [15].

It is necessary to mention that a damage identification algorithm includes four different analysis stages: damage detection, location, quantification and finally, the prediction of the remaining service life and/or residual strength of the structure.

*Address correspondence to this author at the Engineering Department, Universidad Nacional del Sur Av. Alem 1253, 8000 Bahía Blanca, Argentina; Tel: (54 291) 459 5100; Fax: (54 291) 459 5157;

E-mail: nfortega@criba.edu.ar
This paper presents the application of nondestructive methodologies for damage identification, based on the static response of reinforced concrete shells. The first three damage analysis stages, that is, detection, location and quantification are analysed. Furthermore the sensitivities of the different proposed parameters for damage identification, i.e. vertical displacement, elastic curvature, elastic curvature variation and volumetric displacement are investigated.

\section{DAMAGE DETECTION, LOCATION QUANTIFICATION}

AND

As mentioned in the introduction, a damaged structure has less stiffness than an undamaged similar structure. This can be noted in the static response, i.e. through the displacements as well as through the strains produced by acting loads.

The structure displacements and strains are related to its geometry, the mechanical properties of the material and the acting loads. Damage can be due to a change in its designed geometry or a change in the mechanical properties of the material. Three methods, for detection and location of damage, are presented and compared in this paper. They are based on the analysis of their static response and the measured variables are the vertical displacements.

Representative models of reinforced concrete parabolic cylindrical shell, with and without damage, were made. These were analyzed by a commercial software which uses the Finite Elements Method [16]. As a result, the vertical displacement values in different points of the surface were obtained.

It must be kept in mind that the vertical displacement values can be experimentally obtained, measured in the actual structure or in a experimental model to scale, or using a numerical model. The final results of the numerical model will depend, among other things, on the quality of the mesh, mechanical properties of the material, boundary conditions, etc.

2011 Bentham Open 
In relation to experimental measurements, damage prediction accuracy depends on the uncertainty related to measurement errors. Since the methodologies presented are intended for on site use, it must be kept in mind that experimental measurements are sensitive to various factors, namely., temperature, moisture, noise linked to electronic components of apparatus, type of instrumentation used in the experimental measurements such us, LVDT (Linear Variable Differential Transformer), mechanical displacements gauges, the availability of equipment associated with the measurement points density, etc. If there are suspicions that an area in the structure is damaged and the equipment availability is limited, most of the equipment can be placed in the apparently damaged zone, distributing the others in the rest of the structure, with a much lower density.

\section{Numerical Modeling}

Fig. (1a) represents the middle surface geometry of a parabolic cylindrical shell, analyzed in this work. In the direction of the " $\mathrm{x}$ " axis there is a $15 \mathrm{~m}$. The total length, in the direction of the " $y$ " axis, is $40 \mathrm{~m}$ composed of four longitudinal ten meters spans and the shell is supported by $10 \mathrm{~m}$ columns. The model has a $0.30 \mathrm{~m}$ x $0.20 \mathrm{~m}$ longitudinal edge beam. The shell thickness (h) is $0.10 \mathrm{~m}$. The free edges, in the $\mathrm{x}$ direction, have the same thickness as the shell. Steel tensors were located in the match area of the shell and the columns (Fig. 1b).

The parabolic cylindrical shell was modeled with four nodes rectangular plate / shell elements. At the match area of the columns and the tensor the mesh was refined with triangular elements. The columns were modeled with beam elements and the tensors with truss elements. Approximately 8500 plate-shell $0.20 \times 0.40 \mathrm{~m}$ elements were employed in the whole model. The adopted mesh density was chosen to ensure adequate precision in the displacement obtained.

Damage is modeled by means of a change in the structure geometry, through a decrease of the shell thickness at the deteriorated zone that modified the Moment of Inertia. This is a situation that actually occurs, for example when as a consequence of the reinforcement corrosion, the concrete cover falls off, or when an unexpected specific overload acts on the structure, cracking it.

The applied loads correspond to the weight of the structure itself plus a distributed vertical load of $1000 \mathrm{~N} / \mathrm{m}^{2}$.

The material properties for the models are $\mathrm{E}=2.07 \times 10^{10}$ $\mathrm{N} / \mathrm{m}^{2} ; v=0.15$ and $\rho=2405 \mathrm{Kg} / \mathrm{m}^{3}$, corresponding to strength reinforced concrete of $2 \times 10^{7} \mathrm{~N} / \mathrm{m}^{2}(20 \mathrm{MPa})$.

Since shell structures have good mechanical behavior and in general are not sensitive enough to the appearance of reduced dimensions affects on its surface, affected zones of different sizes were modeled (minimal dimensions $0.40 \mathrm{~m} \mathrm{x}$ $0.40 \mathrm{~m}$ ), by means of the decrease in rigidity, varying its thickness to take the damage into account, through a parameter "a", which represents the thickness reduction of the shell in the damaged areas. For example, when $\mathrm{a} / \mathrm{h}=0.4$, the remaining shell thickness (useful thickness from a mechanical point of view) is $60 \%$, but the remaining inertia moment is $22 \%$, due to the fact that the inertia moment is proportional to the thickness cubed, while the damage is increased to values of $\mathrm{a} / \mathrm{h}=0.6$, the remaining shell thickness is $40 \%$ and the remaining inertia moment is $6 \%$.

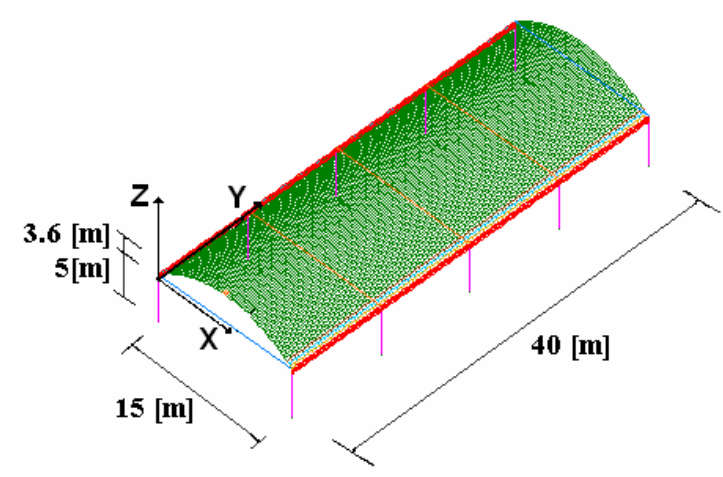

(a) General view

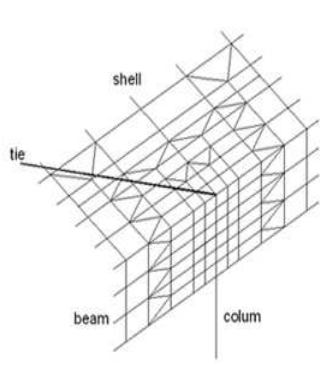

(b) View of the match area of the shell and the columns

(a) General view (b) View of the match area of the shell and the columns

Fig. (1). Reinforced concrete parabolic cylindrical shell model.

\section{Damage Detection and Location}

Depending on the damage location the following methods, permits to do simultaneously detection and localization, or only damage detection:

- Vertical displacement variation;

- Elastic curvature; and

- Elastic curvature variation.

\section{Vertical Displacement Variation Method}

This method is based on the analysis of the parameter corresponding to the percentage difference between the displacements of the undamaged and damaged structure, at each point.

This parameter is an index of its rigidity variation, and is defined as:

$$
\delta_{i}(\%)=\left|\frac{y_{i D}-y_{i U D}}{y_{i U D}}\right| \times 100
$$

Where: $\mathrm{y}_{i D}$ represents the displacement of the point $i$ in the damaged structure, and $y_{i U D}$ the displacement of the same point in the undamaged structure. It is interesting to mention that this methodology was used by the authors [17] in plane structures damage detection. 


\section{Model Analysis with Damage at the Free Edge}

Figs. (2-4) shows the percentage vertical displacement variation of a parabolic cylindrical shell structure with damage on a surface of $0.80 \mathrm{~m} \times 0.80 \mathrm{~m}$ at the free edge. Three damage location at $\mathrm{x}=7.4 \mathrm{~m}$ (Fig. 2); $\mathrm{x}=14 \mathrm{~m}$ (Fig. 3) y $\mathrm{x}=11 \mathrm{~m}$ (Fig. 4) are represented. For each location different damage severities $\mathrm{a} / \mathrm{h}$ are considered. It can be seen here that in the place where the damage is located there is a gradient sign variation of the vertical displacements variations and consequently, the curvature changes.

Figs. (2) and (3) shows that the maximum variation in vertical displacements occurs at the affected zone. Furthermore, this variation is greater when the relation $\mathrm{a} / \mathrm{h}$ increases, that is when the damage severity increases.

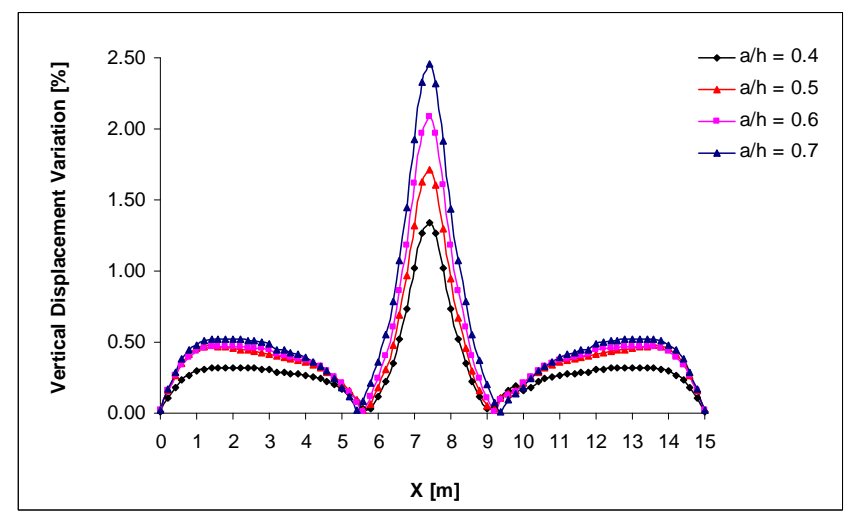

Fig. (2). Vertical displacement variation [\%] with different damage severity at $\mathrm{x}=7.4 \mathrm{~m}, \mathrm{y}=0 \mathrm{~m}$.

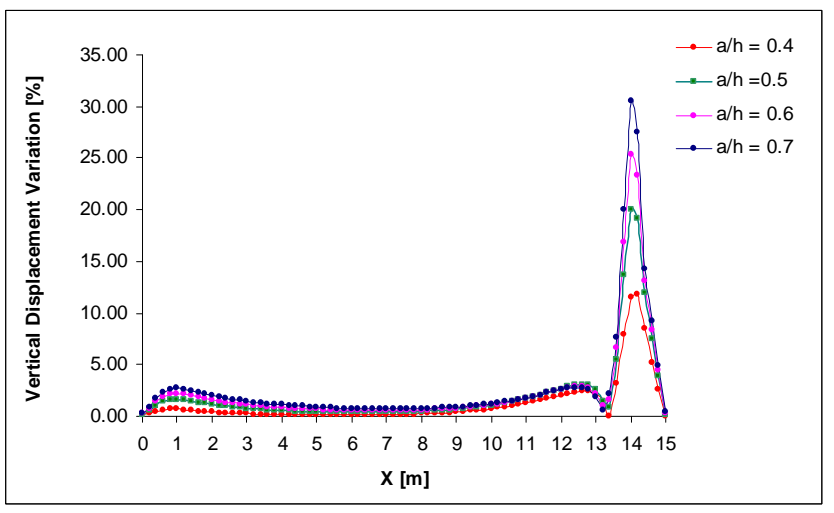

Fig. (3). Vertical displacement variation [\%] with different damage severity at $\mathrm{x}=14 \mathrm{~m}, \mathrm{y}=0 \mathrm{~m}$.

When damage is located at $x=11 \mathrm{~m}$ (Fig. 4), the differences in vertical displacements in relation to damage severity are minimal at that zone, but increase when moves off. This means that the methodology loses sensibility to estimate damage location when the affected zone is located in an intermediate zone between the edge beam and the center of the span (in the $\mathrm{x}$ axis direction).

\section{Model analysis with damage in the central zone of the $\underline{\text { longitudinal span }}$}

Fig. (5), shows the vertical displacement variation when the damage area is located in the central zone of the longitudinal span. An insignificant perturbation appears at the damaged area. A similar behaviour can be observed when the damage is at different locations in the direction of the " $x$ " axis, so it can be concluded that, in this case, the methodology can only be applied for damage detection, for damage location it has no sensibility.

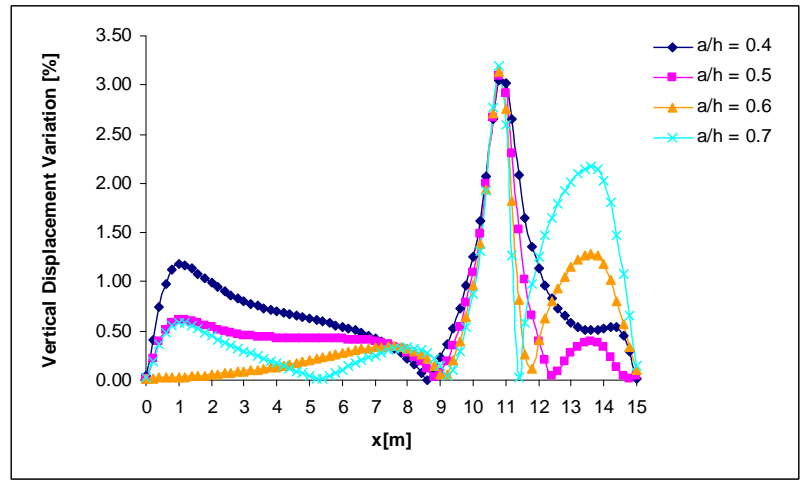

Fig. (4). Vertical displacement variation [\%] with different damage severity at $\mathrm{x}=11 \mathrm{~m}, \mathrm{y}=0 \mathrm{~m}$.

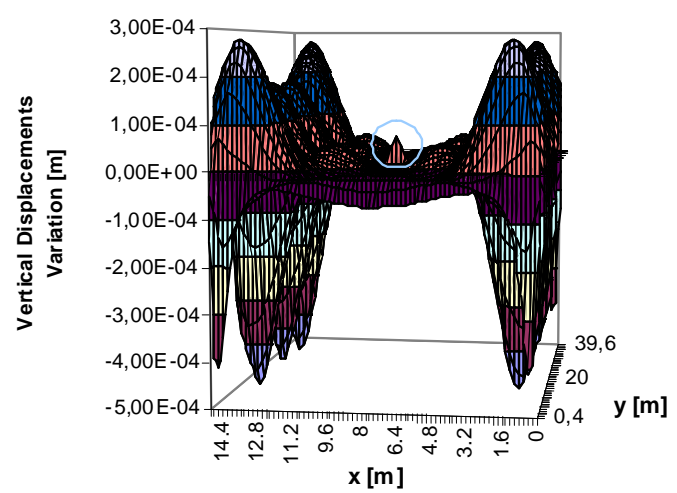

Fig. (5). Vertical displacement variation, with damage at $x=7.4 \mathrm{~m}$, $\mathrm{y}=15 \mathrm{~m}, \mathrm{a} / \mathrm{h}=0.5$.

\section{Model analysis with damage on the tensor zone}

Fig. (6) shows the vertical displacement variation when damage is located on the tensor zone. It can be seen that in this case, there is an important change in the vertical displacements variations (in the zone where damage is located). A similar behaviour can be observed when damage is at different locations in the direction of the " $\mathrm{x}$ " axis, so the methodology can be used for damage detection as well as for damage location.

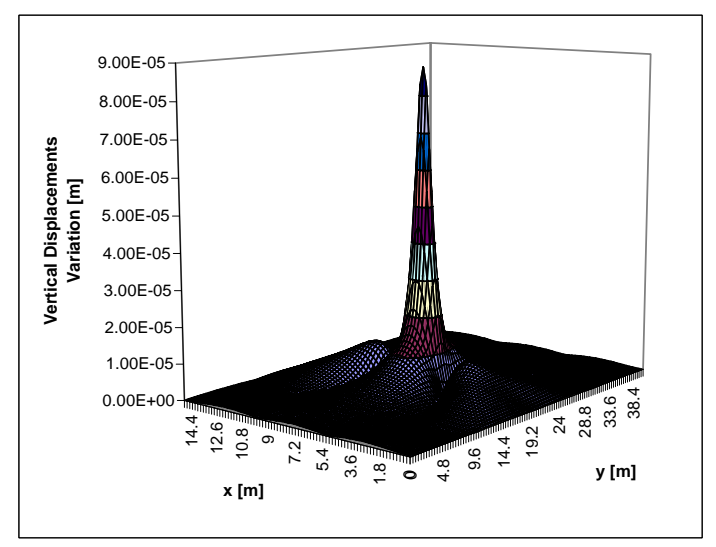

Fig. (6). Vertical displacements variation, with damage at $x=7.4$ $\mathrm{m}, \mathrm{y}=20 \mathrm{~m}, \mathrm{a} / \mathrm{h}=0.5$. 
Regarding the effect of damage on the stress state of the shell, it was found that in the undamaged part, stresses did not exceed $1 \mathrm{MPa}$, by 90 to $95 \%$ of the shell surface, and in the remaining area, did not exceed $5 \mathrm{MPa}$. In the damaged area, in the worst case that is when the damage is located near the support and with a $/ \mathrm{h}=0.7$, the compressive stresses varied between 5 and $9 \mathrm{MPa}$, which are allowable stress values.

\section{Elastic Curvature Method}

The vertical displacement values obtained in certain points of the structure, can be used to obtain the elastic curvature in different points of the deformed structure, by the Central Finite Differences. This way, the curvature is as follow [18]:

$$
\begin{aligned}
& \frac{d^{2} y}{d x^{2}}=\frac{y_{i+1}-2 y+y_{i-1}}{s^{2}} \\
& i=2, \ldots, n-1
\end{aligned}
$$

Where: $s$ represents the distance between two adjacent points (step), whereas $y$, represents the vertical displacement at a certain point and $n$ the number of points available in the mesh.

It is important to mention that this methodology does not depend on the undamaged structure information, which is an advantage when this information is not available.

The graphic of the elastic curvature for an undamaged structure, represents a slight shape, while a peak or a discontinuity in its shape shows an abnormal variation of the rigidity in that position, produced by damage. Hence the damaged area can be localized using this technique

\section{Model analysis with damage at the free edge}

Fig. (7) shows the elastic curvature, calculated according to equation (2), in relation to the location of each point in the mesh, for an structure with damage located at $\mathrm{x}=7.4 \mathrm{~m}$, with a damage severity of $\mathrm{a} / \mathrm{h}=0.5$. Here a pronounced variation of the damaged area can be seen. The same behaviour occurs when the damage location is at $\mathrm{x}=11 \mathrm{~m}$. However, when the affected area is near the columns $(x=14$ $\mathrm{m})$ this pronounced variation is not seen.

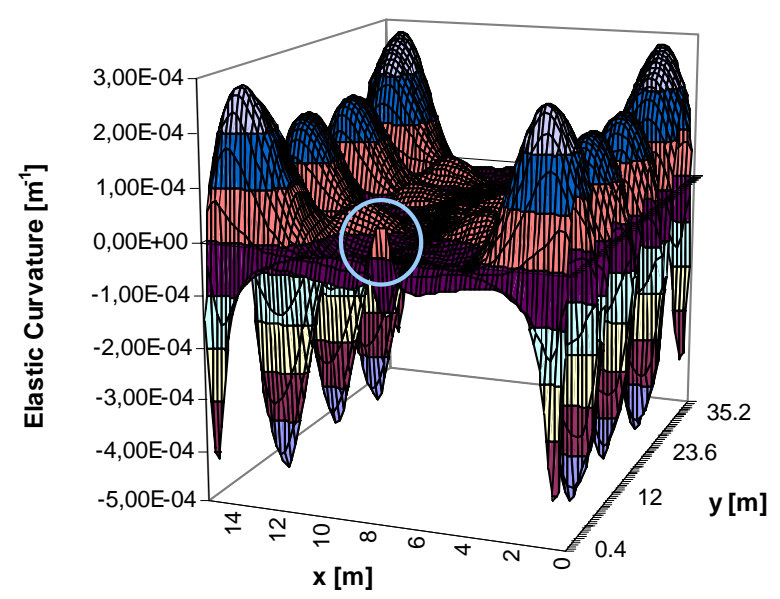

Fig. (7). Elastic curvature, with damage at $x=7.4 \mathrm{~m}, \mathrm{y}=0 \mathrm{~m}, \mathrm{a} / \mathrm{h}=$ 0.5 .
Model analysis with damage in the central zone of the longitudinal span

Fig. (8) represents the elastic curvature, in relation to the location of each point in the mesh, with damage in the position corresponding to $x=14 \mathrm{~m}$ and severity damage $\mathrm{a} / \mathrm{h}$ $=0.5$. As can be appreciated here the damaged area presents a pronounced variation. It is to be noted that when damage is located at the central zone of the span or near the zone located at the quarter of the span (in the $\mathrm{x}$ axis direction) these variations are small. Hence in the last two cases, it is very difficult to detect the existence of damage.

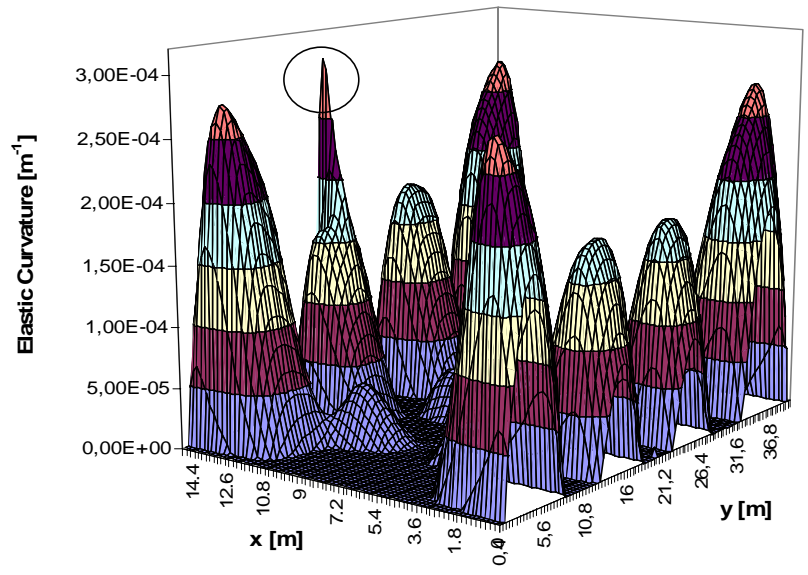

Fig. (8). Elastic curvature, with damage at $x=14 \mathrm{~m}, y=15 \mathrm{~m}, \mathrm{a} / \mathrm{h}$ $=0.5$.

\section{Model analysis with damage at the tensor zone}

Fig. (9) shows the Elastic Curvature in relation to the location of each point in the mesh, with damage at the tensor zone, in the position corresponding to $\mathrm{x}=11 \mathrm{~m}$ and with $\mathrm{a} / \mathrm{h}$ $=0.5$ damage severity. Here that the damaged area presents a pronounced variation and similar behaviour can be seen when damage is near the central zone of the shell. When the damaged zone is located, close to the beam, it does not behave this way, but presents a discontinuity that is difficult to detect.

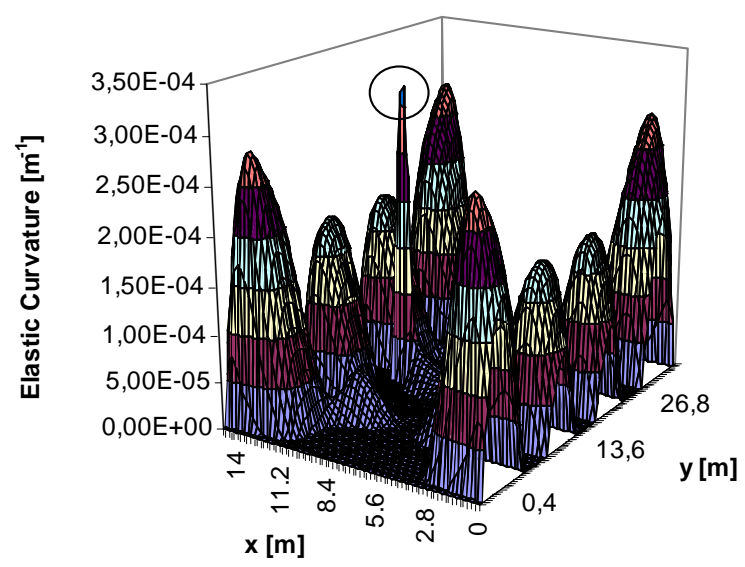

Fig. (9). Elastic curvature, with damage at $\mathrm{x}=11 \mathrm{~m}, \mathrm{y}=20 \mathrm{~m}, \mathrm{a} / \mathrm{h}$ $=0.5$. 


\section{Elastic Curvature Variation Method}

The difference between the curvature of the damaged and the undamaged structure, estimated by means of Equation (2), is used as a parameter for the location of damage, that is:

Elastic Curvature Variation $=\left[\left(\frac{d^{2} y}{d x^{2}}\right)_{d}-\left(\frac{d^{2} y}{d x^{2}}\right)_{u d}\right]$

\section{Model Analysis with Damage on the Free EDGE}

Fig. (10) shows the elastic curvature variation, in relation to the location of each point in the mesh, with damage in the position corresponding to $\mathrm{x}=11 \mathrm{~m}, \mathrm{y}=0$ and with $\mathrm{a} / \mathrm{h}=0.5$ damage severity. This figure shows that the damaged area presents a pronounced variation and similar behaviour is apparent when damage is at $\mathrm{x}=7.4 \mathrm{~m}, \mathrm{x}=14 \mathrm{~m}$ and $\mathrm{y}=0$.

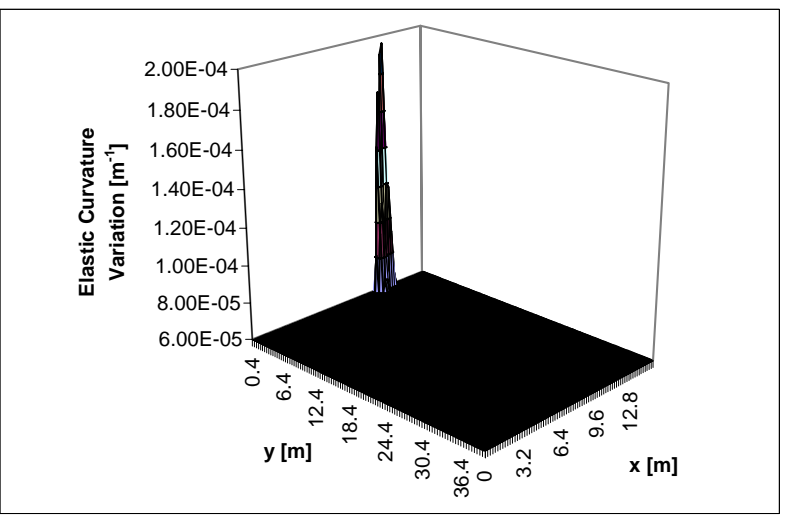

Fig. (10). Elastic curvature variation, with damage at $\mathrm{x}=11 \mathrm{~m}, \mathrm{y}=$ $0 \mathrm{~m}, \mathrm{a} / \mathrm{h}=0.5$.

\section{Model Analysis with Damage in the Central Zone of the Longitudinal Span}

Fig. (11) represents the elastic curvature variation in relation to the location of each point in the mesh, with damage at $\mathrm{x}=11 \mathrm{~m}, \mathrm{y}=15 \mathrm{~m}$ and $\mathrm{a} / \mathrm{h}=0.5$ damage severity. The damaged area presents a pronounced variation; a similar behaviour is noticed when the damaged area is at $\mathrm{x}=7.4 \mathrm{~m}$, $\mathrm{x}=14 \mathrm{~m}$ and $\mathrm{y}=15 \mathrm{~m}$.

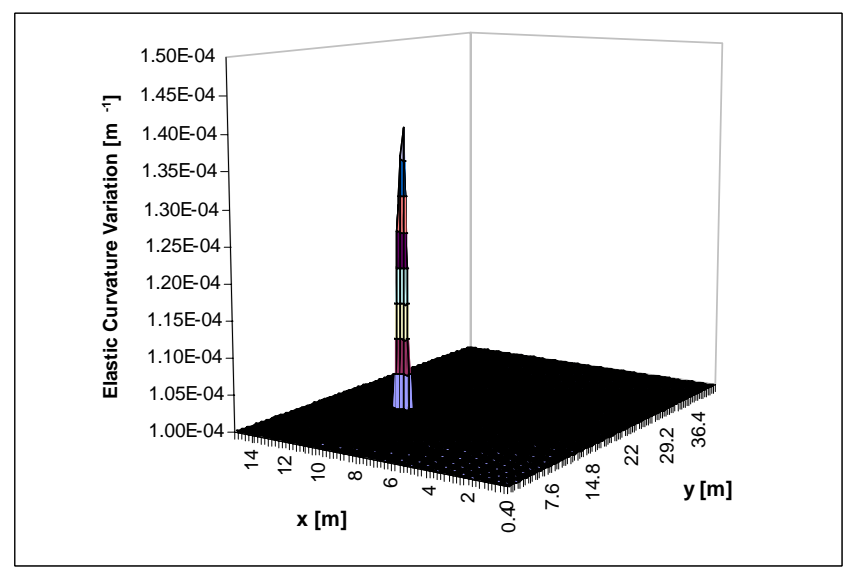

Fig. (11). Elastic curvature variation, with damage at $x=11 \mathrm{~m}, \mathrm{y}=$ $15 \mathrm{~m}, \mathrm{a} / \mathrm{h}=0.5$.

\section{Model Analysis with Damage on the Tensor Zone}

Fig. (12) shows the elastic curvature variation in relation to the location of each point in the mesh, with damage at $\mathrm{x}=11$ $\mathrm{m}, \mathrm{y}=20 \mathrm{~m}$ and damage severity $\mathrm{a} / \mathrm{h}=0.5$. It can be observed that the damaged area presents a pronounced variation; a similar behaviour is noticed when the damaged area is at $\mathrm{x}=7.4 \mathrm{~m}, \mathrm{x}=14 \mathrm{~m}$ and $\mathrm{y}=20 \mathrm{~m}$.

\section{Detection and Location Techniques. Results Analysis}

Table 1 shows the conditions determining whether damage location or only damage detection is possible with the use of the different methodologies presented in this paper.

The technique based on the elastic curvature variation which depends on the information of the undamaged structure, presents a great ability to locate damage in shell structures regardless of the severity of the damage than other methodologies presented.

Table 1. Different Techniques Presented in this Paper and Their Applicability as Detection Technique (D) or Location Technique (L) as a Function of Damage Location

\begin{tabular}{|c|c|c|c|c|}
\hline \multirow{2}{*}{$\begin{array}{l}\text { Location according to } \\
\qquad \text { “y" direction }\end{array}$} & \multirow[t]{2}{*}{ METHODOLOGY } & \multicolumn{3}{|c|}{ Location according to " $x$ " direction } \\
\hline & & $7.4 \mathrm{~m}$ & $11 \mathrm{~m}$ & $14 \mathrm{~m}$ \\
\hline \multirow{3}{*}{ Free Edge Zone } & Vertical Displacement Variation & $\mathrm{L}$ & $\mathrm{L}$ & $\mathrm{L}$ \\
\hline & Elastic Curvature & $\mathrm{L}$ & $\mathrm{L}$ & $\mathrm{D}$ \\
\hline & Elastic Curvature Variation & $\mathrm{L}$ & $\mathrm{L}$ & $\mathrm{L}$ \\
\hline \multirow{3}{*}{ Span Central Zone } & Vertical Displacement Variation & $\mathrm{L}$ & $\mathrm{D}$ & $\mathrm{D}$ \\
\hline & Elastic Curvature & $\mathrm{L}$ & $\mathrm{D}$ & $\mathrm{D}$ \\
\hline & Elastic Curvature Variation & $\mathrm{L}$ & $\mathrm{L}$ & $\mathrm{L}$ \\
\hline \multirow{3}{*}{ Tensor Zone } & Vertical Displacement Variation & $\mathrm{L}$ & $\mathrm{L}$ & $\mathrm{L}$ \\
\hline & Elastic Curvature & $\mathrm{L}$ & $\mathrm{L}$ & $\mathrm{D}$ \\
\hline & Elastic Curvature Variation & $\mathrm{L}$ & $\mathrm{L}$ & $\mathrm{L}$ \\
\hline
\end{tabular}




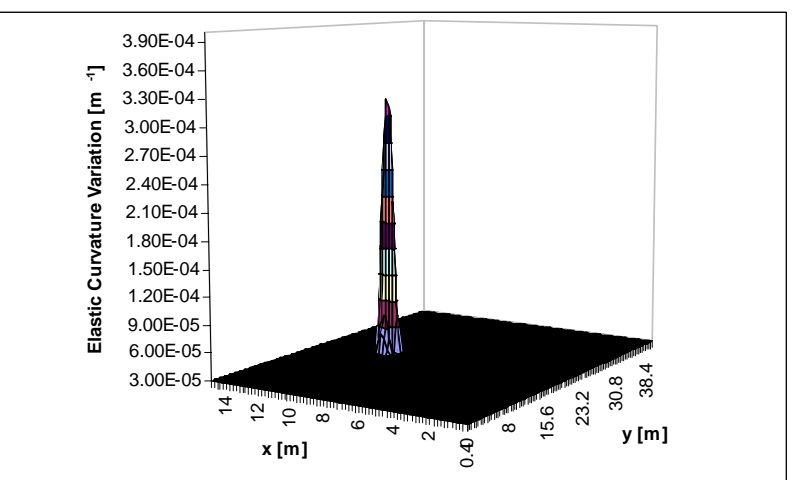

Fig. (12). Elastic curvature variation, with damage at $\mathrm{x}=11 \mathrm{~m}, \mathrm{y}=$ $20 \mathrm{~m}, \mathrm{a} / \mathrm{h}=0.5$.

The methodology based on the vertical displacement variation, in the case of shell structures, can be used for damage detection with good results. For damage location it does not prove to be a good index, because the sensibility of this parameter depends strongly on the location of the damage.

It is important to mention that shell structures possess important surfaces so, it is impossible to assure that the mechanical properties of concrete will remain constant in all its extent. On the other hand it is not always possible to determine the true Modulus of Elasticity in situ. Hence, with the purpose of quantifying the errors produced when an estimation of the concrete properties is used in the analysis, three models with Modulus of Elasticity in a range that correspond with the maximum $\left(\mathrm{E}=3.00 \mathrm{E}+10 \mathrm{~N} / \mathrm{m}^{2}\right)$, average $\left(E=2.07 \mathrm{E}+10 \mathrm{~N} / \mathrm{m}^{2}\right)$ and minimum values $(\mathrm{E}=$ $1.50 \mathrm{E}+10 \mathrm{~N} / \mathrm{m}^{2}$ ) (usual values for this material), were investigated. It was found that, the vertical displacement differences were lower than $10 \%$. Because of this, the error produced when the values of vertical displacements, corresponding to the undamaged structure, are calculated numerically, has no significant influence on the results of the detection, location and quantification of damage. On the other hand if a structure works on dominant flexion, for example a linear frame, depending on the type of loads it is subjected to, the variations in the displacements values, due to the value of the modulus of elasticity, are much more important.

It may be noted that in the case of having more than one damaged area, the methodology for the detection and location of damage applies.

\section{Damage Quantification}

Once the damage has been located through the techniques previously described here, the following step is to establish its magnitude.

Although the damaged area may be visually detected, there is uncertainty as regards its magnitude in the interior of the structure. In order to cope with this, it is necessary to make a numerical model of the structure with the damage simulated in the location determined visually, or located using the methodologies previously presented, or by the use of an experimental technique (for example, ultrasounds).
After locating the damage, its surface area on the shell can be estimated visually, in case of having access, and / or by experimental techniques (for example, ultrasounds), and then, with this information the numerical models can be built.

In this paper, in order to show an application of the technique for quantifying the damage in the structure, models with different location and damage severity are analyzed by means of a numerical method, taking a damage extend of $80 \times 80 \mathrm{~cm}$ and a longitudinal location $\mathrm{y} / \mathrm{L}=0$. As a consequence, graphics in 3 dimensions were obtained in relation to the following parameters: location, severity of damage, and a third parameter related to the mechanical behaviour of the damaged structure. Then, entering the graphic (Fig. 13) with damage position, in the direction of the smaller side of the shell, $\mathrm{x} / \mathrm{L}$ and with the parameter related to the mechanical behaviour of the damaged structure, i.e. vertical displacements, elastic curvature variation or volumetric displacement, the value of the damage severity a/h can be obtained.

The mechanical parameters used in this paper were the elastic curvature variation and the volumetric displacements [19], with the purpose of finding out which of them is more sensitive to damage severity.

The last parameter mentioned above, named in this case vertical volumetric displacement ( $V V D)$, takes into account the variation of the vertical displacements throughout the structure. This parameter can be defined as the summation of the product of the vertical displacement produced in each point of the mesh by its influence volume [20]:

$V V D=\sum_{i=1}^{n} y_{i} \times V_{i}$

Then,

the vertical volumetric displacement has the advantage of taking into account a higher volume of information, so if there were an error in a measurement, it would have a smaller impact on the final result.

\section{Damage quantification results analysis}

Table 2 shows the values of the parameter's vertical volumetric displacements and elastic curvature variation with the corresponding values of the relations $\mathrm{x} / \mathrm{L}$ (location) and $\mathrm{a} / \mathrm{h}$ (severity).

Based on the results presented in Table 2, it is clear that the elastic curvature variation shows an important percentage variation, in the range of severities examined, regardless of the damage location. In the case of the vertical volumetric displacement, the percentage variation is reduced. Hence, considering this low percentage variation, it can be concluded that the vertical volumetric displacement is not a noticeable parameter for damage quantification.

Fig. (13) shows the elastic curvature variation as a function of severity $(\mathrm{a} / \mathrm{h})$ and location $(\mathrm{x} / \mathrm{L})$ of damage. Damage severity can be determined through this graphic if ones get the value of the elastic curvature variation and 
Table 2. Elastic Curvature Variation and Vertical Volumetric Displacement in Relation to the Location and Severity of Damage. Structural Damage at the Free Edge Zone $(\mathrm{y} / \mathrm{L}=0)$

\begin{tabular}{|c|c|c|c|c|c|c|}
\hline \multirow{3}{*}{$\mathbf{a} / \mathbf{h}$} & \multicolumn{3}{|c|}{ Elastic Curvature Variation $\left[\mathrm{m}^{-1}\right]$} & \multicolumn{3}{|c|}{ Vertical Volumetric Displacement $\left[\mathrm{m} . \mathrm{m}^{3}\right]$} \\
\hline & \multicolumn{3}{|c|}{$\mathbf{x} / \mathbf{L}$} & \multicolumn{3}{|c|}{$\mathbf{x} / \mathbf{L}$} \\
\hline & $7.4 / 15$ & $11 / 15$ & $14 / 15$ & $7.4 / 15$ & $11 / 15$ & $14 / 15$ \\
\hline 0.7 & $1.165 \mathrm{E}-4$ & $4.031 \mathrm{E}-4$ & $7.888 \mathrm{E}-4$ & $1.446 \mathrm{E}-1$ & $1.4453 \mathrm{E}-1$ & $1.4525 \mathrm{E}-1$ \\
\hline 0.6 & $1.165 \mathrm{E}-4$ & $2.663 \mathrm{E}-4$ & $3.945 \mathrm{E}-4$ & $1.4459 \mathrm{E}-1$ & $1.4456 \mathrm{E}-1$ & $1.4507 \mathrm{E}-1$ \\
\hline 0.5 & $1.1620 \mathrm{E}-4$ & $1.959 \mathrm{E}-4$ & $3.312 \mathrm{E}-4$ & $1.4458 \mathrm{E}-1$ & $1.4459 \mathrm{E}-1$ & 1.4494E-1 \\
\hline 0.4 & $8.125 \mathrm{E}-5$ & $1.388 \mathrm{E}-4$ & $2.612 \mathrm{E}-4$ & $1.4458 \mathrm{E}-1$ & $1.4463 \mathrm{E}-1$ & $1.4485 \mathrm{E}-1$ \\
\hline$\%$ Variation Min - Max & 30.25 & 65.56 & 66.78 & 0.01 & 0.07 & 0.27 \\
\hline
\end{tabular}

damage location $\mathrm{x} / \mathrm{L}$, in the same way as it was explained in point 2.4 .

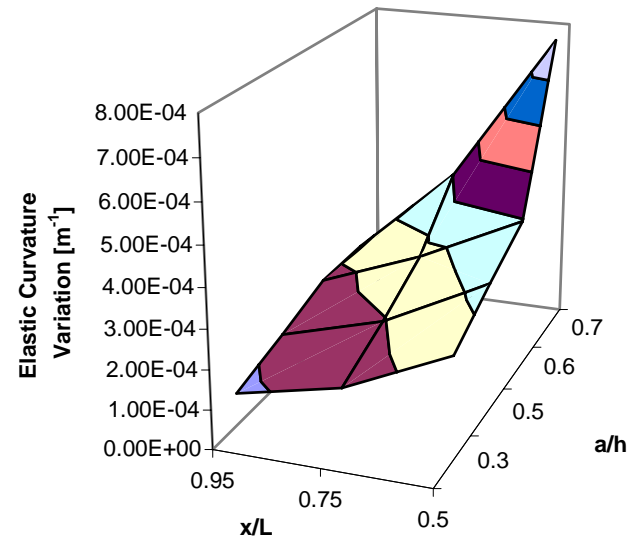

Fig. (13). Elastic curvature variation in relation to location and severity of damage $(\mathrm{y} / \mathrm{L}=0)$.

It may be noted that in the case of having more than one damaged area, the methodology for quantification would only apply when the zones of influence of damaged areas do not overlap, depending on the size of the influence zone for the type of shell considered. It is important to bear in mind that ruled shells are more sensitive to these disturbances, so that areas of influence are greater than in non-ruled shells.

\section{CONCLUSIONS}

The methodologies presented here may be important tools when studying pathologies in shell structures as they can detect, locate and quantify damage, as well as monitor its progress as time goes by, in order to detect the right time for their repair.

It is important to emphasize that for the detection of damage the methodologies here shown Vertical Displacements Variation, Elastic Curvature and Elastic Curvature Variation are applicable. With regard to the location, the most sensitive is the Elastic Curvature Variation.

It must be kept in mind that, in the presented methodologies, the reliability of the results strongly depends on the quality of the vertical displacements measurements made in situ.

\section{ACKNOWLEDGEMENTS}

The authors would like to express their gratitude to the Engineering Department as well as to the General Secretary of Science and Technology of the Universidad Nacional del Sur, for the support given for the development of these investigations.

\section{CONFLICT OF INTEREST}

None declared.

\section{APPENDIX \\ NOTATION}

The following symbols are used in this paper

\begin{tabular}{|c|c|c|}
\hline $\mathrm{a}$ & $=$ & Damage depth \\
\hline h & $=$ & Shell thickness \\
\hline $\mathrm{V}_{\mathrm{i}}$ & $=$ & Influence Volume of point $\mathrm{i}$ \\
\hline VVD & $=$ & Vertical Volumetric Displacement \\
\hline$y_{i D}$ & $=$ & $\begin{array}{l}\text { Displacement of the point } i \text { in the damaged } \\
\text { structure }\end{array}$ \\
\hline$y_{i U D}$ & $=$ & $\begin{array}{l}\text { Displacement of the point } \mathrm{i} \text { in the undamaged } \\
\text { structure. }\end{array}$ \\
\hline & $=$ & Structure displacement variation at each point $\mathrm{i}$ \\
\hline & $=$ & Concrete Modulus of Elasticity \\
\hline & $=$ & Concrete Poisson's ratio \\
\hline
\end{tabular}

\section{REFERENCES}

[1] P. Rizos, N. Aspragathos, and A. Dimagoras, "Identification of crack location and magnitude in a cantilever beam from the vibration modes", J. Sound Vib., vol. 138, no. 3, pp. 381-388, 1990.

[2] A. Dimarogonas, "Vibration of cracked structures: a state of the art review”, Eng. Fract. Mech., vol. 55, no. 5, pp. 831-857, 1996.

[3] O. Salawu, "Detection of structural damage through changes in frequency: a review article", Eng. Struct., vol. 19, no. 9, pp. 718$723,1997$.

[4] X. Yang, S. Swamidas, and R. Seshadri, "Crack identification in vibrating beams using the energy method", J. Sound Vib., vol. 244, no. 2, pp. 339-357, 2001. 
[5] J. Kim, and N. Stubbs, "Crack detection in beam - type structures using frequency data", J. Sound Vib., vol. 259, no. 1, pp. 145-160, 2003.

[6] G. Owolabi, A. Swamidas, and R. Seshadri, "Crack detection in beams using changes in frequencies and amplitudes of frequency response functions", J. Sound Vib., vol. 256, pp. 1-22, 2003.

[7] N.F. Ortega, and S.I. Robles, "Modelo Numérico para predecir la Vida Residual de vigas de hormigón, con sus armaduras afectadas por la corrosión". In Proceedings of $16^{\circ}$ Reunión Técnica de la Asociación Argentina de Tecnología del Hormigón, Mendoza, 2006, pp. 291-298.

[8] Z. Zembaty, M. Kowalski, and S. Pospisil, "Dynamic identification of a reinforced concrete frame in progressive states of damage", Eng. Struct., vol. 28, pp. 668-681, 2006.

[9] J. Chou, and J. Ghaboussi, "Genetic algorithm in structural damage detection", Comput Struct, vol. 79, pp. 1335-1353, 2001.

[10] T. Sain, and J.M. Chandra Kishen, "Damage and residual life assessment of structures using fracture mechanics", In: Proceedings of the $16^{\text {th }}$ ASCE Engineering Mechanics Conference (EM03 Electronic Proceedings), Seatle, 2003, p. 13.

[11] Y . Choi, J.S. Lee, E . Choi, and H.N. Cho, "Development of elastic damage load theorem for damage detection in statically determinate beam", Comput. Struct., vol. 82, pp. 2483-2492, 2004.

[12] D. Maity, and A. Saha, "Damage assessment in structures from changes in static parameter using neural networks", Sadhana, vol. 29, no. 3, pp. 315-327, 2004.
[13] S. Suresh, S.N. Omkar, R. Ganguli, and V. Mani, "Identification of crack location and depth in a cantilever beam using a modular neural network approach", Smart. Mater Struct., vol. 13, pp. 907915, 2004.

[14] A. Caddemi, and A. Morassi, 2005. "A procedure for multiple damage identification in elastic beams", In: Proceedings of $6^{\text {th }}$ World Congress on Structural and Multidisciplinary Optimization, Río de Janeiro, Brazil, 2005, p. 10.

[15] F. Jiang, A. Rohatgi, K.S. Vecchio, and R.R. Adharapurapu, "Crack length calculation for bend specimens under static and dynamic loading", Eng. Fract. Mech., vol. 71, pp. 1971-1985, 2004.

[16] Algor20 Professional Mech/VE. Docutech, Linear Stress and Dynamics, Pittsburgh: Algor Reference Division, 2007.

[17] S.I. Robles, and N.F. Ortega, "Detección de daños en elementos estructurales lineales", In: Proceedings of the ENIEF 2005, Buenos Aires, vol. 24, 2005, pp. 2759-2777.

[18] Q. Lu, G. Ren, and Y. Zhao, "Multiple damage location with flexibility curvature and relative frequency change for beam structure", J. Sound Vib., vol. 253, no. 5, pp. 1101-1114, 2002.

[19] N.F. Ortega, and J.V. Arias, "Comparison of mechanical efficiency between an hyperbolic paraboloid and an experimental model". In: Proceedings of the IV World Congress on Computational Mechanics (IV WCCM), Buenos Aires, 1998, pp. 2324-2339.

[20] S.I. Robles, and N.F. Ortega, "Study of volumetric displacements of shells", J. Int. Assoc. Shell Spat. Struct., vol. 42, no. 137, pp. 139-147, 2001

(C) Robles and Ortega; Licensee Bentham Open.

This is an open access article licensed under the terms of the Creative Commons Attribution Non-Commercial License (http://creativecommons.org/licenses/by-nc/3.0/) which permits unrestricted, non-commercial use, distribution and reproduction in any medium, provided the work is properly cited. 